\title{
Using Cyclical Regimes of Output Growth to Predict Jobless Recoveries
}

\author{
Michael J. Dueker
}

\begin{abstract}
Gaps between output and employment growth are often attributed to transitional phases by which the economy adjusts to shifts in the rate of trend productivity growth. Nevertheless, cyclical factors can also drive a wedge between output and employment growth. This article shows that one measure of cyclical dynamics-the expected output loss associated with a recession-helps predict the gap between output and employment growth in the coming four quarters. This measure of the output loss associated with a recession can take unexpected twists and turns as the recovery unfolds. The empirical results in this paper support the proposition that a weaker-than-expected rebound in the economy can partially mute employment growth for a time relative to output growth.
\end{abstract}

Federal Reserve Bank of St. Louis Review, March/April 2006, 88(2), pp. 145-53.

\section{"} n like a lamb, out like a lamb" is a common refrain one hears about business recessions. The assertion is that the robustness of the recovery is proportional to the severity of the contraction phase of a cyclical downturn (Wynne and Balke, 1992). If this is true, a socalled jobless recovery might be considered part and parcel of a mild recession. But, beware the Ides of March because this argument misses the point that a jobless recovery is a big event-the cost of a business cycle downturn rises substantially if the economy does not enjoy a snapback phase of above-trend growth following a contraction in output.

The degree to which people expect that a contraction in output will not be undone in the future can be measured as the expected output loss associated with an economic downturn. In this article, I develop a measure of expected output loss from recession. In some recessions, the timing and relative magnitude of expected output loss closely mirrors the widely used Hodrick-Prescott measure of the output gap. In the recoveries from the past two recessions-both of which were labeled jobless recoveries-the expected permanent output loss looks much worse than the output gap, in terms of both magnitude and duration. This article demonstrates that one can use this output loss measure as a predictor of the extent to which output growth will outpace employment growth at least six months ahead.

This article provides empirical evidence that cyclical forces significantly influence the gap between output and employment growth, in addition to the effects that shifts in trend productivity generate. Wen (2005) uses a rational expectations model to show that firms optimally hoard labor in anticipation of stronger demand for their goods. If the economy's rebound from a recession is weaker than anticipated, firms might find that they had been holding too much labor, resulting in a period of muted employment growth.

\section{MEASURING EXPECTED OUTPUT LOSS FROM A RECESSION}

A key part of this article's perspective on the consequences of recessions is that the snap-back,

Michael J. Dueker is an assistant vice president and an economist at the Federal Reserve Bank of St. Louis. Andrew Alberts provided research assistance.

(C) 2006, The Federal Reserve Bank of St. Louis. Articles may be reprinted, reproduced, published, distributed, displayed, and transmitted in their entirety if copyright notice, author name(s), and full citation are included. Abstracts, synopses, and other derivative works may be made only with prior written permission of the Federal Reserve Bank of St. Louis. 
high-growth phase the economy experiences following a recession has a random duration. In many recessions, the snap-back phase lasts long enough such that the output loss associated with the recession is 1 percent or less. From this vantage point, a so-called jobless recovery occurs when the snap-back phase lasts an unexpectedly short time or is skipped altogether. In general, labor productivity continues its upward trend during the recession, so by the end of the recession the effective, productivity-adjusted labor input is high relative to output. This ratio can return to its equilibrium value either through above-normal growth in output or below-normal growth in employment. In a jobless recovery, the latter predominates, although the reasons for this outcome are not always clear.

This article assumes that each recovery from a recession is the result of stochastic transitions between output growth states. Simply not enough data exist at this point to parameterize these transitions as functions of novel labor market patterns. Gordon (1993) and Schreft and Singh (2003, p. 65), in contrast, offer a structural change perspective on jobless recoveries. The latter authors posit that changes in the labor market may contribute to a greater tendency toward jobless recoveries going forward. They suggest that "justin-time employment lets firms wait to see that a recovery is robust before hiring, yet still expand production on short notice by hiring temps and using overtime." Aaronson, Rissman, and Sullivan (2004) concur that just-in-time hiring practices played an important role in the recovery from the 2001 recession.

To build an empirical model of jobless recoveries, I use a model of output growth in which the expected output loss associated with a recession could undergo sizable changes between the start and the end of the recovery. ${ }^{1}$ To do this, I estimate a four-state Markov switching model, with four distinct growth states for real gross domestic product (GDP). Real GDP growth is denoted $y$ and the growth states are $\mu_{i}$ :

1 Engemann and Owyang (2006) also present an empirical model of jobless recoveries.

$$
\begin{aligned}
& y_{t}=\mu_{S_{t}}+e_{t} \\
& e_{t} \sim N\left(0, \sigma^{2}\right) \\
& S_{t}=i, i=1, \ldots, 4 \\
& \mu_{1}<\mu_{2}<\mu_{3}<\mu_{4} .
\end{aligned}
$$

In this set-up, the fourth state has the highest growth rate and, therefore, will represent the snap-back growth. A jobless recovery will be one where state 4 is either skipped or is shorter than in other recoveries.

\section{Related Empirical Models of Asymmetric Cycles}

The four-state Markov switching model of GDP growth falls within a large class of models of asymmetric business cycles. For a model of output growth, asymmetry implies that the fluctuations above and below the unconditional mean growth rate are not mirror images. Sichel (1993) described particular attributes that the asymmetry might have, including asymmetries in steepness and deepness. McQueen and Thorley (1993) added asymmetry in sharpness. Clements and Krolzig (2003) noted that a two-state Markov switching model cannot imply an asymmetry in steepness. The four-state Markov switching model will generally display all three types of asymmetry.

Sichel (1994) suggested that the rebuilding of inventories implied three states in U.S. economic activity: normal growth, recession, and a snap-back phase of high growth following a recession, as inventories were restocked. Kim, Morley, and Piger (2005) effectively add to a two-state Markov switching model a third state whose timing and length are deterministic functions of the preceding recession state. Van Dijk and Franses (1999) similarly extend two-state threshold autoregressive models so that they have multiple regimes but in a framework where predetermined transition variables determine the regime, leaving no room for contemporaneous surprises regarding the regime. This framework, however, does not reflect the public perception that jobless recoveries are unpleasant surprises. For this reason, I use a four-state Markov switching model where all transitions between regimes are stochastic. 


\section{Estimates of the Four-State Markov Switching Model}

The transition probabilities for the Markov states are

(2) $\operatorname{Prob}\left(S_{t}=i \mid S_{t-1}=j\right)=p_{i j}, i=1, \ldots 4 ; j=1, \ldots, 4$.

This leads to a matrix of transition probabilities that enter the likelihood function, $l_{t}$, which is expressed as a prediction-error decomposition:

(3) $\sum_{t} I_{t}=\sum_{t} \ln \left(\sum_{i} \operatorname{Prob}\left(S_{t}=i \mid y_{t-1}\right) f\left(y_{t} \mid S_{t}=i\right)\right)$.

The results of estimating the model for quarterly U.S. chain-weighted real GDP growth from 1958:Q1 to 2005:Q3 are shown below. The estimated growth states (expressed as annual rates) and their unconditional probabilities are as follows:

$$
\begin{aligned}
& \mu_{i}, i=1, \ldots, 4=
\end{aligned}
$$

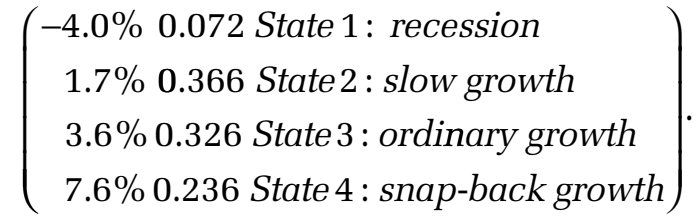

Figure 1 plots GDP growth against the probability-weighted fitted value, using the smoothed-state probabilities. It is remarkable that, using either the filtered or smoothed probabilities, the weighted average of the four growth states explains enough of the dynamics in GDP growth that the residuals show no significant serial correlation. In fact, after 1994 the degree of serial correlation in the residuals is even lower than for the full sample, despite the model finding fewer transitions in the growth states. In contrast, in a twostate model—e.g., Hamilton (1989)—it is necessary to model GDP growth as an autoregressive process to remove the serial correlation. Figure 2 shows the smoothed probabilities of the snap-back, highgrowth state. The recoveries from the 1990-91 and 2001 recessions were the times when this snapback phase was largely absent.

The transition probability matrix has entries such that $\operatorname{Prob}\left(S_{t}=i \mid S_{t-1}=j\right)=p_{i j}$ appear in row $i$ and column $j$ :

$$
\left(\begin{array}{llll}
0.267300 & 0.133134 & 9.18590 e-08 & 0.0163723 \\
0.607963 & 0.612537 & 0.0533640 & 0.342089 \\
0.0156676 & 0.0249191 & 0.946636 & 0.0302375 \\
0.109070 & 0.229411 & 2.22045 e-16 & 0.611301
\end{array}\right) .
$$

Note that standard errors are not reported for these maximum-likelihood parameter estimates because the estimated information matrix is not positive definite, given that several transition probabilities lie near the boundary of the parameter space, i.e., zero.

The transition probability matrix shows that the probability that the economy will shift from either the recession state or the low-growth state straight to the ordinary growth state without passing through the fast, snap-back growth state 4 is low $\left(p_{41}=0.109\right)$. Also, there is a good chance that the economy could bounce back and forth more than once between the low-growth state 2 and the snap-back growth state 4 before entering the relatively persistent ordinary growth state $3\left(p_{21}=\right.$ 0.608 and $p_{12}=0.133$ ). It is quite likely, according to this transition matrix, that the economy will spend a nontrivial period of time in the snap-back growth state following a recession. In fact, the unconditional probability of the economy being in the snap-back growth state is almost 24 percent. Based on this model, one would expect that much of the output loss from a recession would be undone by the snap-back state. The fact that there is no transition from the persistent ordinary growth state 3 to the snap-back growth state 4 ( $p_{43}$ is essentially zero) means that a recovery will remain "jobless" if the ordinary growth state takes hold before much snap-back growth has taken place.

Given the accrued output loss to date from a recession and the filtered probabilities of the current state, one can use this Markov switching model to calculate, at each quarter following the onset of the recession, an expected value of the output loss associated with that recession. Figure 3 illustrates a hypothetical example, based on the parameter estimates from the four-state Markov switching model. In this example, we calculate the expected output loss from a recession that started four quarters ago. In the four quarters that have already ensued, the first quarter was in the 


\section{Figure 1}

GDP Growth and Fitted Value from Four-State Markov Model Using Smoothed State Probabilities

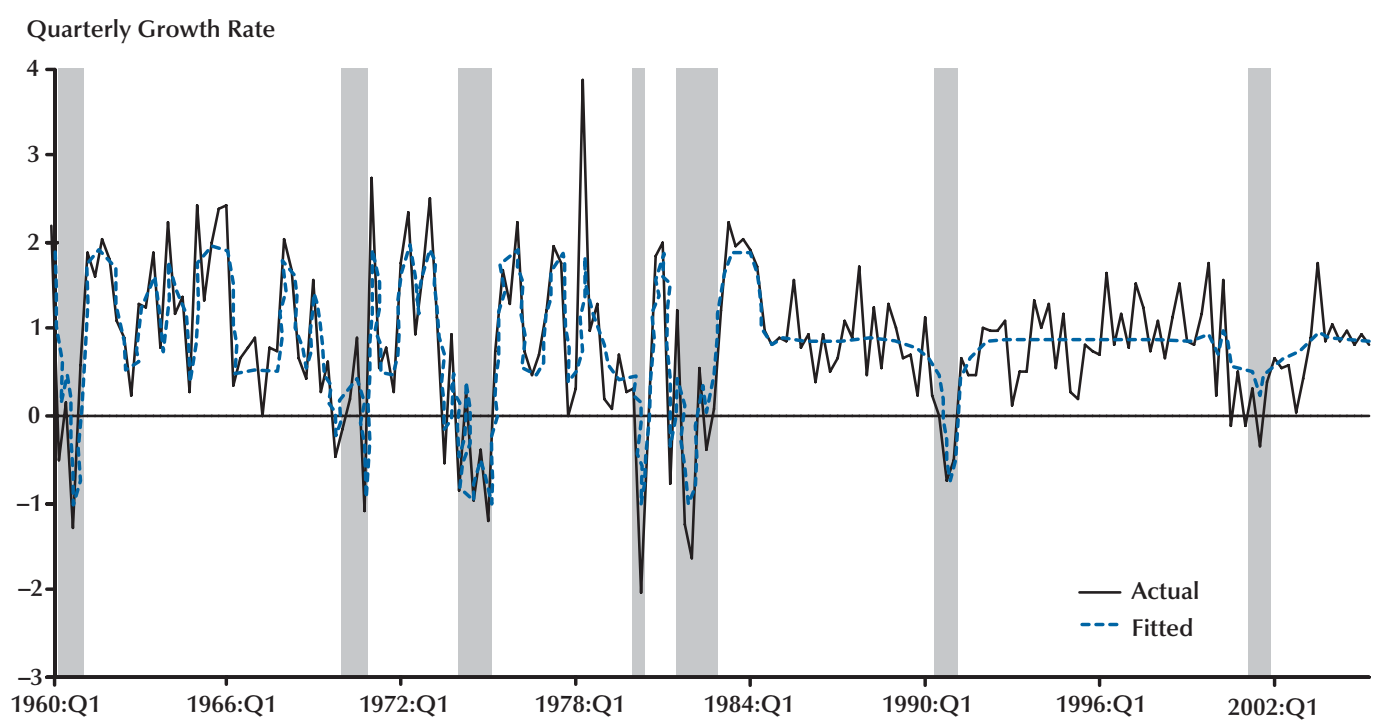

Figure 2

Smoothed Probability of Fast-Growth State 4

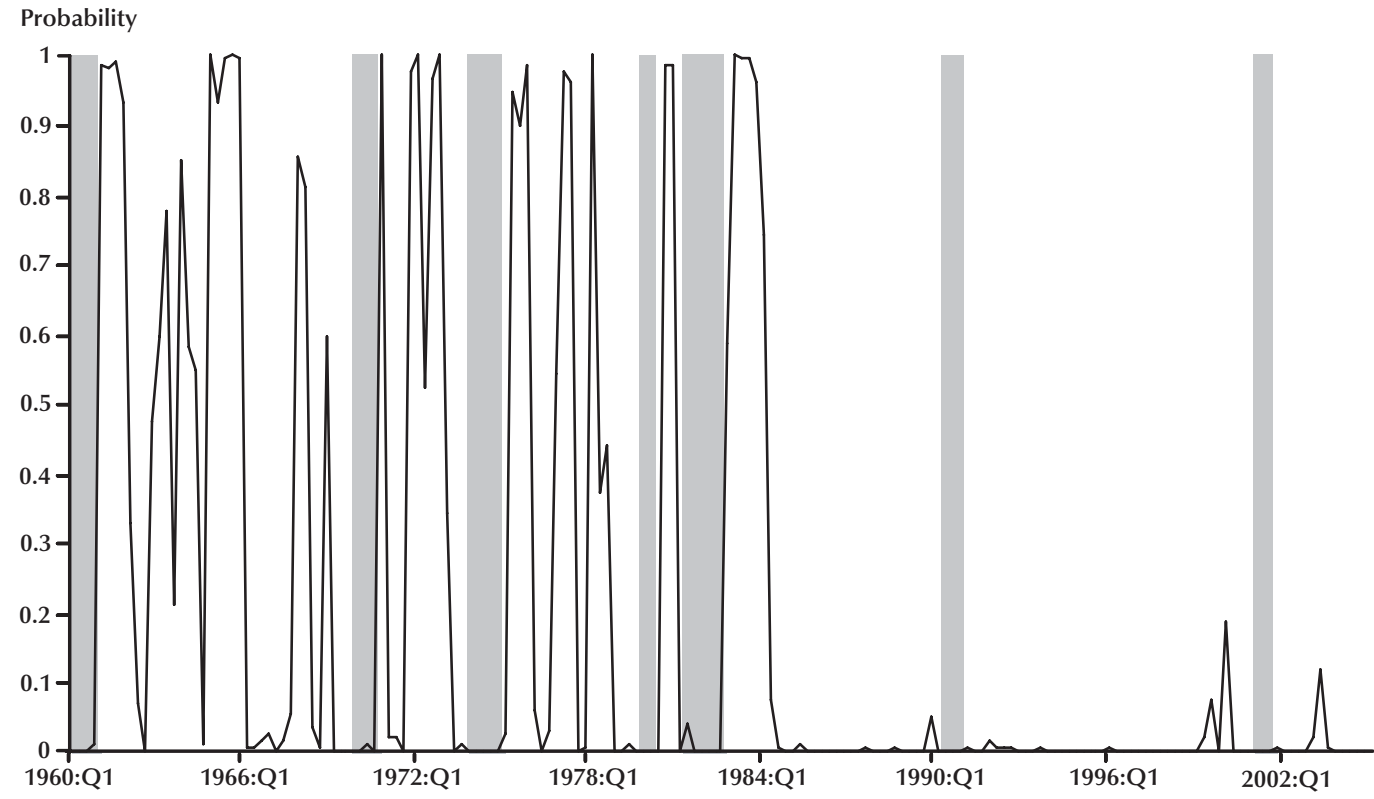




\section{Figure 3}

\section{Path of Expected Output Four Quarters After the Onset of a Hypothetical Recession}

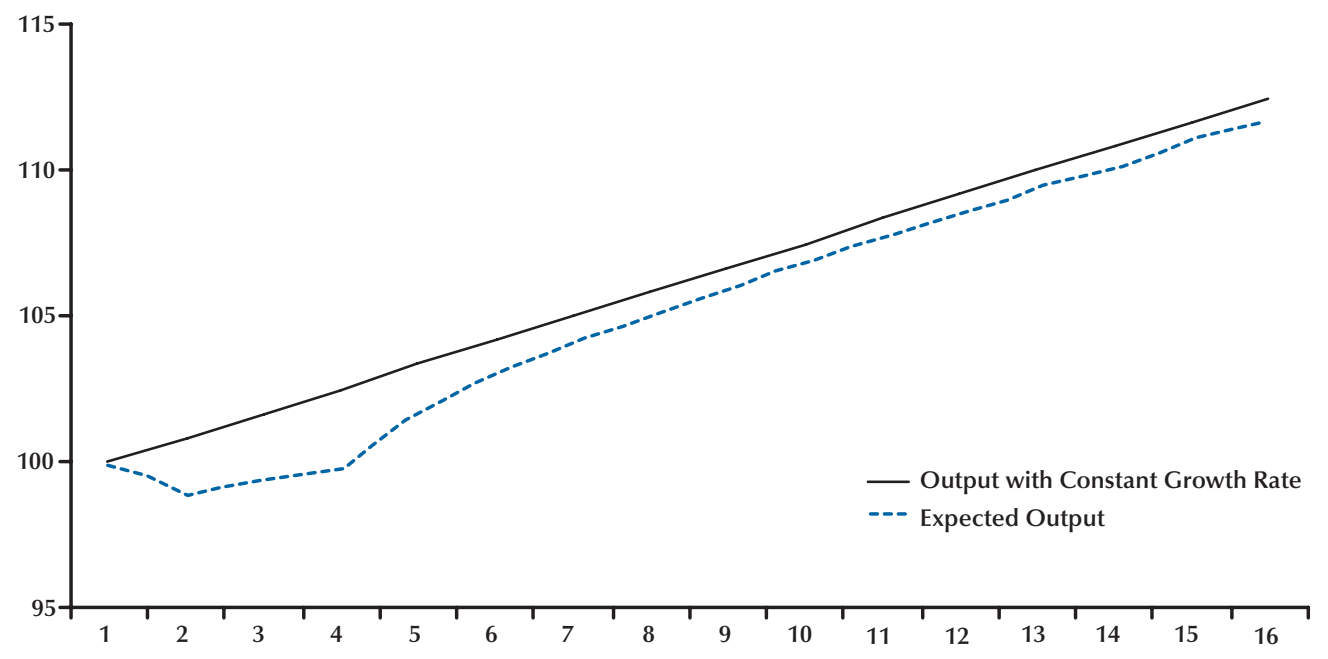

recessionary state 1 , the next two were in the slow-growth state 2 , and the fourth was in the snap-back state 4 . From that point, the model is simulated many times $(4,000)$ to arrive at an expected path for the level of output. I compare this path with a reference path in which output grew at a constant rate equal to the model-implied unconditional growth rate (0.83 percent per quarter) for the entire time. Provided that the length of the simulated path is long enough so that the probabilities of the four growth states converge to their unconditional probabilities and the implied growth rate becomes fixed at its unconditional value (0.83), the ending point of the simulation will provide a measure of the long-run or "permanent" output loss associated with the recession. With the transition probabilities estimated here, a simulation length of 40 quarters is more than sufficient to converge to the unconditional probabilities. Thus, in this example plotted in Figure 3, the expected long-run output loss from the hypothetical recession is about 0.7 percent, with the expectation taken four quarters after the onset of the hypothetical recession.

Using the unconditional, constant-growth path described above as a reference path, we can calculate this measure of expected long-run output loss at each quarter following the onset of each recession in our sample. Throughout the recession itself, the expected output loss will become larger because, for every quarter that the economy remains in recession, the probability that the economy will remain in recession for an aboveaverage length of time increases. As with any duration, the right tail of the distribution is inevitably longer than the left tail, since there is no way that today's situation can last for an arbitrarily shorterthan-expected time, but it can last for an arbitrarily longer-than-expected time. As the economy begins to recover from the recession, however, the expected output loss associated with the recession recedes in accordance with the number of quarters spent in the snap-back growth state.

Figure 4 plots the average across all U.S. recessions since 1960 of the expected long-run output loss as a function of quarters since the onset of recession. Across all recessions, the snap-back growth state occurs for enough quarters to undo most of the output loss associated with the preceding recession. Across all recessions, after 18 quarters, the expected long-run output loss is about 1 percent. In this light, we can see why the past two jobless recoveries-following the 1990-91 and the 2001 recessions-disappointed the public. 
Figure 4

Expected Effect on Output from Recession, Calculated at Each Quarter from Recession Onset

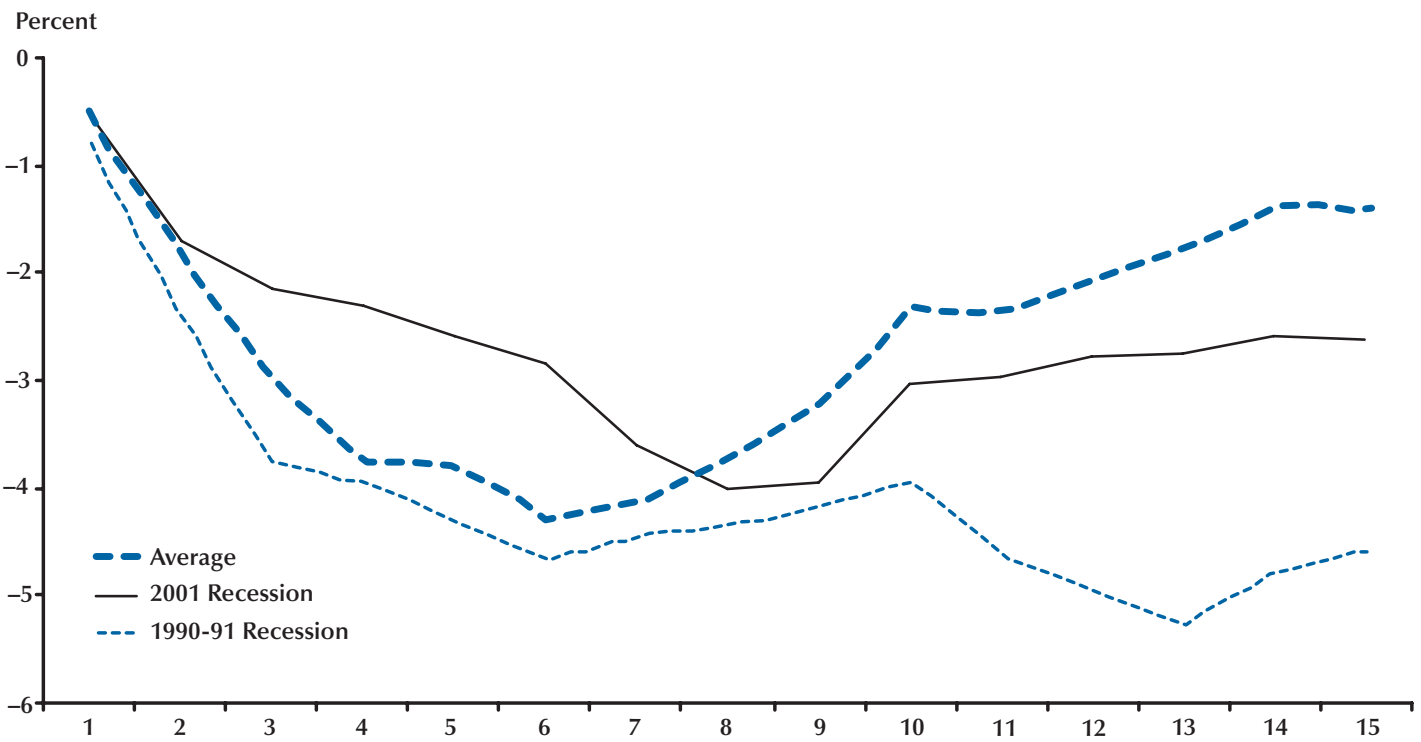

Figure 5

Expected Long-Run Effect on Output from Recession and HP Output Gap

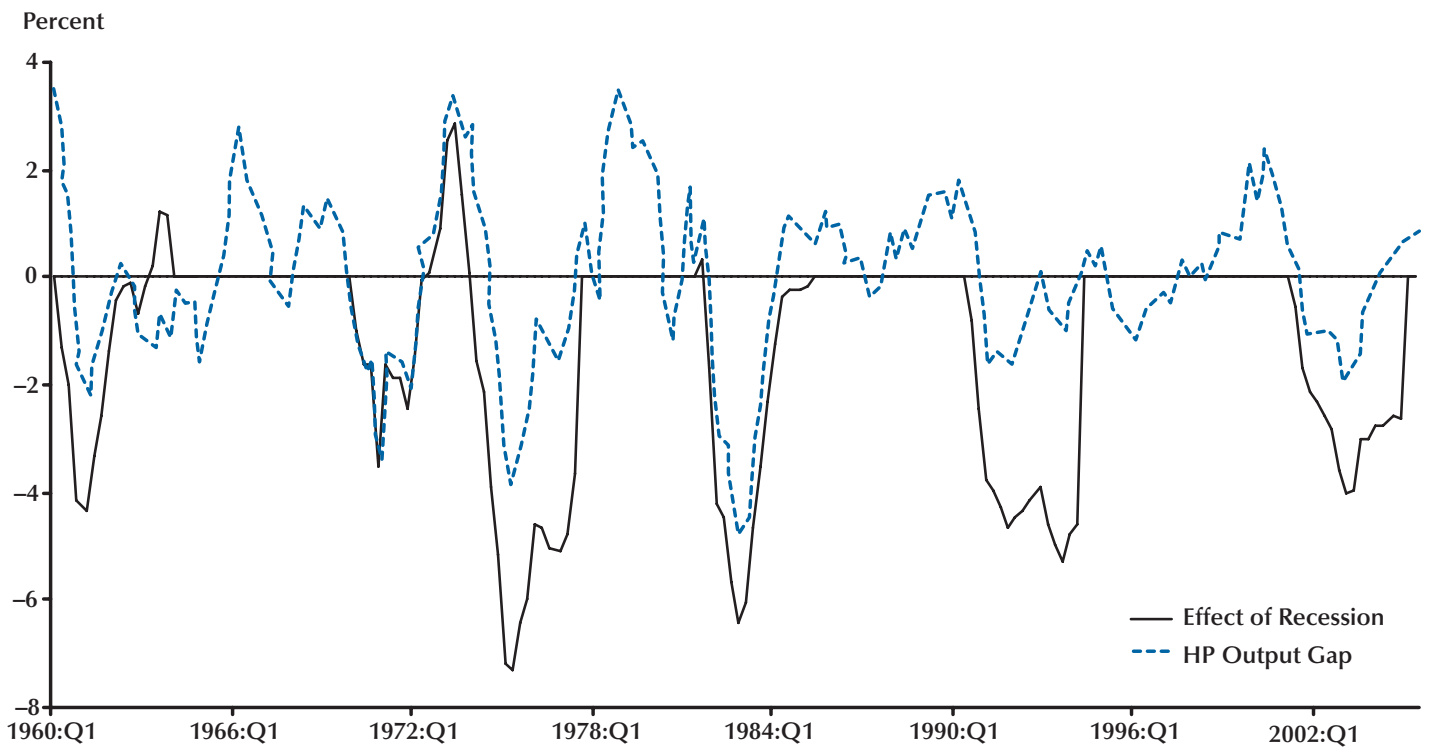


Since neither recession lasted an unusually long time, the path of expected output loss was fairly typical, or even slightly milder than normal, during the actual recessions. Yet, the failure to spend a considerable length of time in the snap-back phase following the recession-especially in the aftermath of the 1990-91 recession-meant that the usual diminution of expected output loss failed to materialize. Figure 4 shows that the expected output losses associated with the 1990-91 and 2001 recessions were well above the typical 1 percent-4.5 and 2.6 percent, respectively-15 quarters after recession onset.

Figure 5 plots the expected output loss following each recession since 1960 alongside the widely used Hodrick-Prescott measure of the output gap. Note that the short 1980 recession, in which the recovery melded with the start of another recession in 1981, is excluded from the output loss calculations. Also, the expected output loss converges to a constant after about 15 quarters. At that point, the output loss from the recession essentially has been realized and is no longer an expected value. Nor are expectations of the future related to the value of the output loss measure at this point, so those observations beyond 15 quarters are dummied out of the expected output loss measure in Figure 5.

Figure 5 shows that the correspondence between the expected output loss and the HodrickPrescott output gap is fairly close for the 1960-61, 1969-70, and 1981-82 recessions. In contrast, the expected output loss measure makes the 1974-75, 1990-91, and 2001 recessions look worse than the output gap does. In the case of the 1974-75 recession, the economy did spend time in the snap-back growth state, as seen in Figure 1. It did not spend enough time in that state, however, to overcome the large output loss accrued during the recession. Figure 1 shows a contrasting picture for the jobless recoveries after the 1990-91 and 2001 recessions, when the economy spent minimal time in the snap-back growth state. For this reason, the output loss from the past two recessions was quite large in relation to the maximum size that the output gap attained.

\section{PREDICTING CYCLICAL GAPS BETWEEN OUTPUT AND EMPLOYMENT GROWTH}

One well-known disadvantage of HodrickPrescott filtering is that the two-sided nature of the filter makes filtered data inappropriate for use in prediction models. The filtered value at time $t$ is a function of future values of the data. The expected output loss measure, in contrast, was constructed from unsmoothed regime probabilities, using information only through time $t$. Thus, the only sense in which the expected output loss measure is constructed from future information is through the full-sample parameter estimates. This parameter channel, however, is a very weak source of future information in comparison with a two-sided filter. Consequently, I examine how well the expected output loss measure can be used to predict the effect that business cycle dynamics will have on the gap between output and employment growth.

To test the importance of such a cyclical channel in the determination of the gap between output and employment growth, I regressed the gap between quarterly GDP growth and employment growth (the log change in aggregate payroll employment):

$$
\Delta y_{t}-\Delta n_{t}=\mu+\gamma_{i} \text { ELoss }_{t-1}+\varepsilon_{t},
$$

where $y$ is the log of GDP, $n$ is the log of employment, and ELoss is the expected output loss from recession. The coefficient on $\gamma_{i}$ is significant for lag lengths from $i=1$ through 4 quarters. Table 1 presents the estimates of $\gamma_{i}, i=1, \ldots, 4$ and shows that the expected output loss is a significant predictor of the gap between output and employment growth at each horizon up to four quarters. I then estimated the same equation for the four-quarter moving average of the gap, allowing for three moving-average terms to account for the serial correlation induced by the overlapping data. This specification answers the question of whether the expected output loss is a significant predictor of the gap between output and employment growth in the coming year: 
Figure 6

\section{Expected Long-Run Effect on Output from Recession (Lagged One Year) and Moving Average of Gap Between Output and Employment Growth}

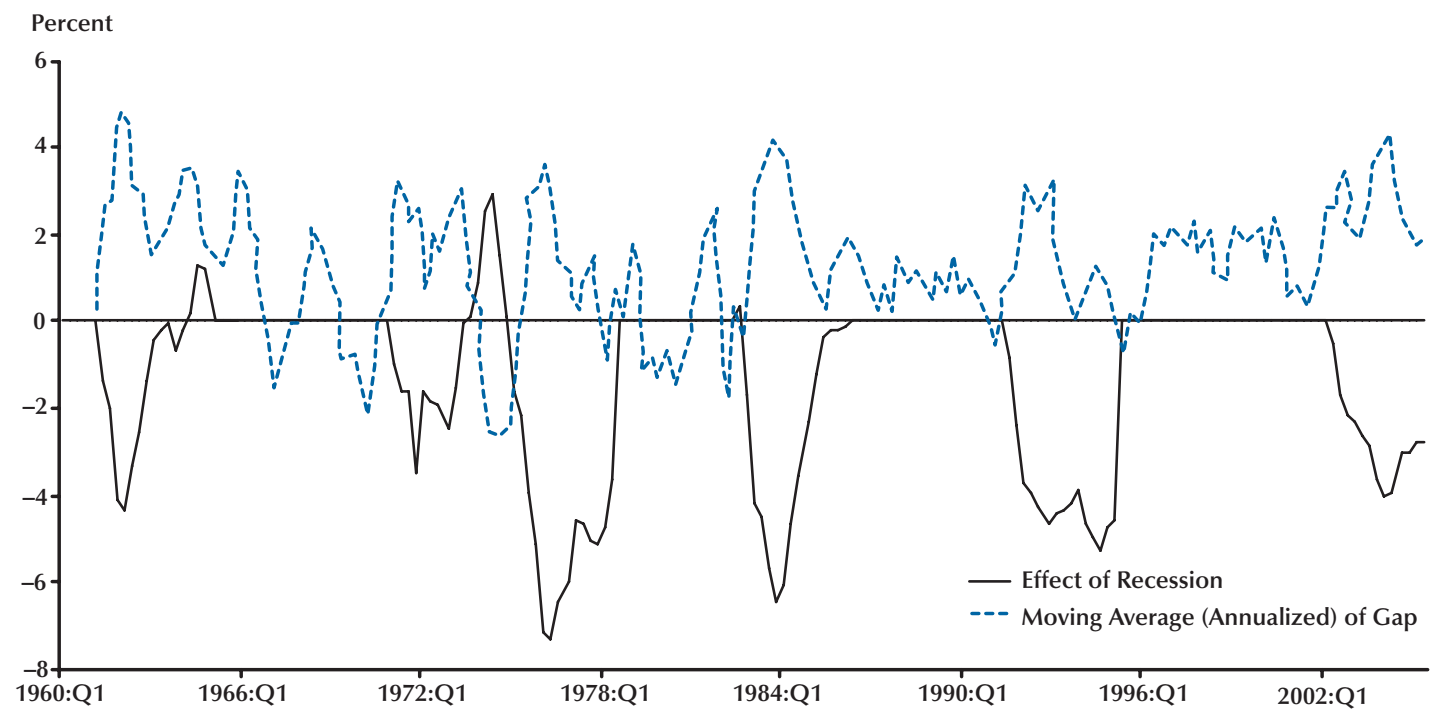

\section{Table 1}

\section{Using Expected Output Loss from Recession to Explain the Gap Between Output and Employment Growth}

\begin{tabular}{lcc} 
Parameter & Value & Standard error \\
\hline \multicolumn{2}{l}{ Period-by-period specifications } & equation (4) \\
$\gamma_{1}$ & -0.100 & $(0.023)$ \\
$\gamma_{2}$ & -0.085 & $(0.023)$ \\
$\gamma_{3}$ & -0.071 & $(0.023)$ \\
$\gamma_{4}$ & -0.054 & $(0.023)$ \\
\multicolumn{4}{l}{ Moving-average specification - equation } & $(5)$ \\
$\Gamma$ & -0.038 & $(0.012)$ \\
$\theta_{1}$ & 0.998 & $(0.043)$ \\
$\theta_{2}$ & 0.933 & $(0.049)$ \\
$\theta_{3}$ & 0.851 & $(0.041)$
\end{tabular}

(5)

$$
\begin{aligned}
& 1 / 4 \sum_{j=0}^{3}\left[\Delta y_{t-j}-\Delta n_{t-j}\right]= \\
& \mu+\Gamma E \operatorname{Loss}_{t-4}+\sum_{k=1}^{3} \theta_{k} \varepsilon_{t-k}+v_{t} .
\end{aligned}
$$

Not surprisingly, given the period-by-period results, the estimated value of $\Gamma$ is also a significant predictor of the gap between output and employment growth in the following year. Table 1 includes the estimates of $\Gamma$ and the moving-average coefficients $\theta_{k}, k=1, \ldots, 3$.

The reason for the significant $\Gamma$ coefficient in the moving-average specification from equation (6) becomes clear in a plot of the expected output loss from recession with the moving average of the gap between output and employment growth in the subsequent four quarters. Figure 6 plots these two variables together. Figure 6 shows the tendency for one to be the negative image of the other, and this relationship has held throughout the sample, not only for the two most recent jobless recoveries. 


\section{SUMMARY AND CONCLUSION}

This article uses a four-state Markov switching model of U.S. GDP growth to derive a novel measure of the time path of expected output loss associated with each recession since 1960. A key feature that distinguishes this model of snap-back growth is that the occurrence and length of the snap-back state are allowed to be random. Thus, the expected output loss from a recession is still evolving after the recession has ended, in accordance with the strength of the recovery. One key feature of the estimated Markov model is that once the economy enters the ordinary growth state, it cannot return directly to the snap-back state. Thus, once a strong recovery has been skipped or has ended early, the expected output loss from the preceding recession is essentially known, and not just an expected value, at that point.

For many recessions, especially 1960, 1969, and 1981, the expected long-run output loss measure corresponds closely with the HodrickPrescott measure of the output gap. For the recessions where the long-run output loss was larger than average, such as 1974,1990 , and 2001, the expected output loss measure makes those downturns look more severe in comparison with the output gap measure. The constructed measure of the expected output loss associated with a recession is a significant predictor of the gap between output and employment growth in the coming four quarters, which could help policymakers identify jobless recoveries as they unfold.

\section{REFERENCES}

Aaronson, Daniel; Rissman, Ellen R. and Sullivan, Daniel G. "Assessing the Jobless Recovery." Federal Reserve Bank of Chicago Economic Perspectives, Second Quarter 2004, 28(2), pp. 2-20.

Clements, Matthew and Krolzig, Hans-Martin. "Business Cycle Asymmetries: Characterization and Testing Based on Markov Switching Autoregressions." Journal of Business and Economic Statistics, January 2003, 21(1), pp. 196-211.
“A Bayesian Analysis of Jobless Recoveries.” Unpublished manuscript, Federal Reserve Bank of St. Louis, 2006.

Gordon, Robert J. “The Jobless Recovery: Does it Signal a New Era of Productivity-Led Growth?” Brookings Papers on Economic Activity, 1993, pp. 271-306.

Hamilton, James D. “A New Approach to Economic Analysis of Nonstationary Time Series and the Business Cycle.” Econometrica, March 1989, 57(2), pp. 357-84.

Kim, Chang-Jin; Morley, James and Piger, Jeremy. "Nonlinearity and the Permanent Effects of Recessions." Journal of Applied Econometrics, January 2005, 20(2), pp. 291-309.

McQueen, Grant and Thorley, Steven. "Asymmetric Business Cycle Turning Points.” Journal of Monetary Economics, June 1993, 31(3), pp. 341-62.

Schreft, Stacy and Singh, Aarti. "A Closer Look at Jobless Recoveries.” Federal Reserve Bank of Kansas City Economic Review, Second Quarter 2003, pp. 45-73.

Sichel, Daniel E. "Business Cycle Asymmetry: A Deeper Look.” Economic Inquiry, April 1993, 31(2), pp. 224-36.

Sichel, Daniel E. "Inventories and the Three Phases of the Business Cycle.” Journal of Business and Economic Statistics, July 1994, 12(3), pp. 269-77.

Van Dijk, Dick and Franses, Phillip H. "Modeling Multiple Regimes in the Business Cycle.” Macroeconomic Dynamics, September 1999, 3(3), pp. 311-40.

Wen, Yi. "On the Optimal Volume of Labor Hoarding." Working Paper 2005-040, Federal Reserve Bank of St. Louis, 2005.

Wynne, Mark A. and Balke, Nathan. "Are Deep Recessions Followed by Strong Recoveries?” Economic Letters, June 1992, 39(2), pp. 183-89.

Engemann, Kristie M. and Owyang, Michael T. 
